Article

\title{
Advances in Laser Additive Manufacturing of Cobalt-Chromium Alloy Multi-Layer Mesoscopic Analytical Modelling with Experimental Correlations: From Micro-Dendrite Grains to Bulk Objects
}

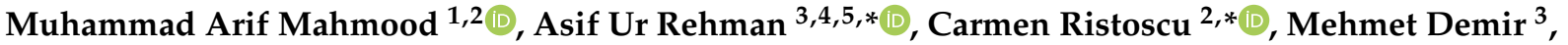 \\ Gianina Popescu-Pelin ${ }^{2}$, Fatih Pitir ${ }^{3}$, Metin Uymaz Salamci ${ }^{4,5}$ (D) and Ion N. Mihailescu ${ }^{2}$ (D)
}

check for updates

Citation: Mahmood, M.A.; Ur Rehman, A.; Ristoscu, C.; Demir, M.; Popescu-Pelin, G.; Pitir, F.; Salamci, M.U.; Mihailescu, I.N. Advances in Laser Additive Manufacturing of Cobalt-Chromium Alloy Multi-Layer Mesoscopic Analytical Modelling with Experimental Correlations: From Micro-Dendrite Grains to Bulk Objects. Nanomaterials 2022, 12, 802. https://doi.org/10.3390/ nano12050802

Received: 14 December 2021 Accepted: 24 February 2022 Published: 26 February 2022

Publisher's Note: MDPI stays neutral with regard to jurisdictional claims in published maps and institutional affiliations.

Copyright: (C) 2022 by the authors Licensee MDPI, Basel, Switzerland. This article is an open access article distributed under the terms and conditions of the Creative Commons Attribution (CC BY) license (https:// creativecommons.org/licenses/by/ $4.0 /)$.
1 Mechanical Engineering Program, Texas A\&M University at Qatar, Doha P.O. Box 23874, Qatar; muhammad.arif_mahmood@outlook.com

2 Laser Department, National Institute for Laser, Plasma and Radiation Physics (INFLPR), 077125 Magurele, Ilfov, Romania; gianina.popescu@inflpr.ro (G.P.-P.); ion.mihailescu@inflpr.ro (I.N.M.)

3 ERMAKSAN, Bursa 16065, Turkey; mehmetdemir4994@gmail.com (M.D.); fatih.pitir@ermaksan.com.tr (F.P.)

4 Department of Mechanical Engineering, Gazi University, Ankara 06570, Turkey; msalamci@gazi.edu.tr

5 Additive Manufacturing Technologies Research and Application Center-EKTAM, Gazi University, Ankara 06560, Turkey

* Correspondence: asyf.rehman@gmail.com (A.U.R.); carmen.ristoscu@inflpr.ro (C.R.); Tel.: +90-539-9387-8001 (A.U.R.); +40-214-574-243 (C.R.)

\begin{abstract}
This study presents two analytical models for the laser powder bed fusion (LPBF) process To begin, the single layer's dimensions were measured using principal operating conditions, including laser power, laser scanning speed, powder layer thickness, and hatch distance. The single-layer printing dimensions were transformed into multi-layer printing using the hatch distance. The thermal history of the printed layers was used as an input to the Johnson-Mehl-Avrami-Kolmogorov model to estimate the average dendrite grain size. LPBF experiments were conducted for a Cobalt-chromium (Co-Cr) alloy to validate the developed model. The average dendrite grain size was estimated using a scanning electron microscope (SEM) combined with "Image J" software. The Vickers hardness test was performed to correlate the average dendrite grain size and operating conditions. A 10-15\% mean absolute deviation was presented between experiments and simulation results. In all samples, a Co-based $\gamma$-FCC structure was identified. An inverse correlation was established between the laser power and smaller average dendrite grain, while a direct relationship has been determined between laser scanning speed and average dendrite grain size. A similar trend was identified between hatch distance and average dendrite grain size. A direct link has been determined between the average dendrite grain size and hardness value. Furthermore, a direct relationship has connected the laser volume energy density and hardness value. This study will help experimentalists to design operating conditions based on the required grain size and corresponding mechanical characteristics.
\end{abstract}

Keywords: laser powder bed fusion; Cobalt-chromium alloy; dendrite grain size; hardness; mesoscopic analytical modelling

\section{Introduction}

The additive manufacturing (AM) process can produce three-dimensional (3D) parts, by utilizing layer-upon-layer technique, via a computer-aided design (CAD) model [1]. AM has been successfully applied in medical [2,3], aerospace [4], automotive [5], and various industrial applications [6]. The Hall-Petch relationship identifies that the material's active strength depends on the grain size such that strength elevated by decreasing the average grain size [7]. From literature, it has been identified that the developed grains are 
characterized via average size, developed phases, and positioning [8]. Average grain sizes can be measured using experimental and simulation techniques.

Various experiments have been carried out to correlate the operating conditions with the average grain size. Laser additive manufacturing (LAM) techniques can be classified into laser powder bed fusion (LPBF) and laser melting deposition (LMD) [9-11]. The rate of heating and solidification play an important role on the final average grain size grain size [12-14]. The shape, microstructure, and mechanical properties of LAM-produced 316L stainless steel specimens were investigated $[15,16]$. It was found that the operating parameters, especially the heat input, play an important role in defining the manufactured part's grain size. The authors identified that the deposited grains contained austenite grains. Recently, an infrared red camera was applied to monitor the grain evolution in the case of AISI 316L stainless steel based on the heating and cooling rates involved in LAM [17]. It was identified that the cooling rate controls the size of developed grain. In another study, experiments were performed to develop a correlation between number of the deposited layers and average grain size [18]. It was found that with an increase in number of layers, the material experiences thermal cyclic loading, leading to reduced grain size. An investigation was carried out to identify the significant parameters to in the case of titanium alloy-AM [19]. For this purpose, a response surface approach was applied, which assisted in defining optimum parameters.

For LAM processes, the finite element (FE) and analytical simulation software systems have recently been introduced to analyze the grain size. Recently, the heat-transfer model was linked with the cellular automata (CA) model to simulate the grain formation [20]. In another study, a 3D heat distribution model was linked with 3D CA model to predict the 3D grain evolution [21-23]. Besides FE simulations, analytical models were also developed by linking the heat distribution model with the Johnson-Mehl-Avrami-Kolmogorov (JMAK) model in combination with heating and cooling rates of the part [24]. All the developed models were able to estimate results with a reliable accuracy.

In this study, efforts have been carried out to establish a correlation among primary operating conditions, average grains size, and hardness value. For multi-layers printing via the LPBF process, an analytical model has been developed to estimate the dimensions of the deposited layers and corresponding average size and hardness. For this purpose, an analytical solution was initially inferred to calculate the single layer's dimensions, including height, width, and depth. The single-layer printing was converted into multi-layers printing using a hatch distance. The developed thermal history was used in correlation with the JMAK model [25] to calculate average grain size in the case of multiple layers. To verify the model for multi-layers printing, experiments were carried out for the LPBF of $\mathrm{Co}-\mathrm{Cr}$ alloy. The average grain size was counted using a scanning electron microscope (SEM). To develop a correlation between operating conditions and hardness value, Vickers hardness testing was carried out.

\section{Mathematical Modelling}

Laser powder bed fusion (LPBF) is an additive manufacturing method developed to liquefy and fuse powder particles via a laser beam. Figure 1 shows the schematic of the LPBF process. Using a mounted piston, the substrate moves downward, giving a space of single-layer thickness. The powder is then uniformly distributed by a powder re-coater (distributor). The laser beam melts the powder and deposits the first layer, which is regulated and guided by $x-y$ scanning mirrors and $f-\theta$ lens. Following that, the substrate descends to deposit the subsequent layer. The 3D component, designed using computeraided design/computer-aided manufacturing (CAD/CAM) software, is manufactured by repeating the abovementioned steps [26]. 


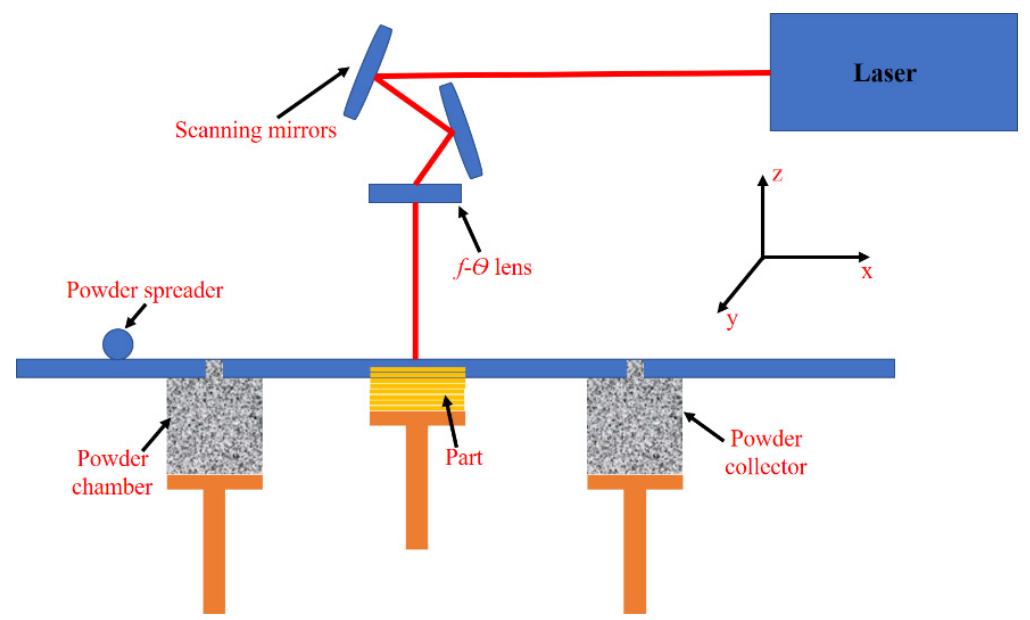

Figure 1. Schematic of the laser powder bed fusion process.

To develop analytical relations for the dimensions of the printed layer, the following assumptions have been taken into account:

Assumptions 1. The speed of the laser beam $\left(V_{s}\right)$ is constant, and the focused laser spot is circular. The printed layer's shape is taken as elliptical and surface tension has been neglected. The thickness (h) of the deposited layer is known.

Assumptions 2. The laser beam energy dissipation by the powder granules is constant, and the powder particles' mean size is taken into consideration [27,28]. While forming a powder bed, the overlapping by the powder particles is ignored. The laser beam absorption and reflection are considered by a cumulative factor, laser absorption coefficient $(\alpha)$.

Assumptions 3. To deposit the n-number of layers, the primary operating conditions such as laser power, laser scanning speed, hatch distance, and powder layer thickness were kept constant.

Assumptions 4. The overlapping (OL) of deposited layers is a hatch distance $(H)$ function. For simplicity, the OL between two layers has been represented by an Equilateral triangle having a height $\left(Z^{*}\right)$, designated as $O L$ intersection.

\subsection{Single Layer Printing}

In the LPBF process, the printed layer's width is usually determined by the powder particles' melting state. Here, the printed layer's width is defined by regime's width $(2 q)$ where the powder elements are melted and can be calculated via the Gaussian distribution expression, as in ref. [29]:

$$
P(q)=\frac{2 P}{\pi r_{l}^{2}} \exp { }^{\left(\frac{-2 q^{2}}{r_{l}^{2}}\right)}
$$

Here, $P$ is the laser power, and $r_{l}$ is the radius of the laser spot. The complete melting of powder particles, from ambient $\left(T_{o}\right)$ to melting temperature $\left(T_{m p}\right)$, requires the energy $\left(E_{m p}\right)$, calculated as [30]:

$$
E_{m p}=\frac{4}{3} \pi r_{p}^{3} \rho_{p} C_{p}^{*} .
$$

In Equation (2), $r_{p}$ is the mean radius of powder particles, $\rho_{p}$ is the density of powder bed and $C_{p}^{*}$ is the modified specific heat value of the powder bed. The $\rho_{p}$ and $C_{p}$ values are calculated as ref. [31]:

$$
\begin{aligned}
\rho_{p} & =(1-\varepsilon) \rho_{b} . \\
C_{p} & =(1-\varepsilon) C_{b} .
\end{aligned}
$$


Here, $\rho_{b}, C_{b}$ and $\varepsilon$ are the density of the bulk material, the specific heat of the bulk material, and voids fraction in the powder bed, respectively. $\varepsilon$ is calculated as:

$$
\varepsilon=1-\frac{\pi r_{p}^{2}}{S}
$$

where $S$ is the powder bed (PB) surface area, expressed as:

$$
S=\pi r_{p b}^{2} \text {. }
$$

Here, $r_{p b}$ is the radius of the powder bed table. In Equation (2), $C_{p}^{*}$ is calculated as [30]:

$$
C_{p}^{*}=\frac{L_{f p}}{T_{m p}-T_{o}}+C_{p} .
$$

Here, $L_{f p}$ is the enthalpy of fusion for a powder bed and $T_{o}$ is the room temperature. $T_{m p}$ is expressed as:

$$
T_{m p}=T(x, y)-T_{\text {loss }} .
$$

$T(x, y)$ is the laser-powder layer interaction temperature, while $T_{\text {loss }}$ is the temperature loss from the area where the laser beam heats the powder layer. $T(x, y)$ is expressed as [31]:

$$
T(x, y)=T_{o}+\frac{P \alpha}{4 \pi R k} \exp \left(\frac{V_{s}(R+x)}{2 K_{p}}\right) .
$$

Here, $P$ is the laser power, $V_{s}$ is the laser speed, $k$ is the thermal conductivity of powder layer and substrate, $K_{p}\left(=k / \rho_{p} C_{p}\right)$ is the thermal diffusivity of the bulk substrate, $\alpha$ is the laser absorption coefficient of the powder particles and $R$ is the distance from the laser beam to the substrate, expressed as:

$$
R=\sqrt{x^{2}+y^{2}+z^{2}}
$$

The correlation between laser power $(P)$, laser intensity $(I)$, and laser spot $\left(r_{l}\right)$ is expressed as [32]:

$$
P=\frac{I \pi r_{l}^{2}}{2}
$$

By substituting the above expression in Equation (9) will give:

$$
T(x, y)=T_{o}+\frac{I r_{l}^{2} \alpha}{8 R k} \exp \left(\frac{V_{s}(R+x)}{2 K_{p}}\right) .
$$

The heat loss from the area where laser beam heats the powder $(Q)$ is expressed as [33]:

$$
Q=U A\left(T(x, y)-T_{o}\right) .
$$

Here, $U$ is the heat transfer coefficient of powder particles, and $A$ is the area of the laser beam incident on the powder layer. $Q$ can be converted from power to temperature as [34]:

$$
T_{\text {loss }}=\frac{Q t}{m H_{\text {cap }}} .
$$

In Equation (14), $m$ is the mass of the printed layer, $H_{c a p}$ is the heat capacity of the powder layer and $t$ is the laser-powder layer interaction time. Equations (15) and (16) give the analytical relations for $t$ and $m$ as [30]:

$$
t=\frac{2 r_{l}}{V_{s}}
$$




$$
m=\frac{Q_{m}}{V_{s}} .
$$

Here, $V_{s}$ is the laser scanning speed and $Q_{m}$ is the powder mass delivered by the powder re-coater (see Figure 1) and its analytical expression will be explained later. The energy balance can be applied on one of the powder particles as [30]:

$$
E_{m p}=\alpha \pi r_{p}^{2} t \frac{2 P}{\pi r_{l}^{2}} \exp { }^{\left(\frac{-2 q^{2}}{r_{l}^{2}}\right)} \text {. }
$$

As discussed above, the relation between the 1st printed layer's width $\left(W_{1}\right)$ and position $(q)$ where the powder particles are melted entirely, is expressed using the following expression [30]:

$$
W_{1}=2 q .
$$

The value of $q$ can be calculated after comparing Equations (2) and (16), which is substituted in Equation (16) to calculate the expression for $W_{1}$ as:

$$
W_{1}=1.414 r_{l}\left[\ln \left\{\frac{2 r_{p} \rho_{p} C_{p}^{*} \pi r_{l}^{2} V_{s}}{3 \alpha P D}\right\}\right]^{\frac{1}{2}} .
$$

It is worth mentioning that the thickness of the powder layer $\left(t_{p l}\right)$ is known and given as an input in the LPBF equipment. However, the laser melting and melt flow redefine the final thickness of the printed layer. In this study, the thickness of the layer has been assumed as the height of the printed layer. After estimating the 1st printed layer width, the law of mass conservation can be applied to calculate the 1st layer height $\left(h_{1}\right)$ as [30]:

$$
\forall_{2} Q_{m} t=\pi \frac{W_{1}}{2} \frac{h_{1}}{2} V_{s} t \rho_{p} .
$$

In Equation (20), $Q_{m}$ is calculated as:

$$
Q_{m}=\rho_{p} V_{r c} t_{p l} l_{r c},
$$

where $V_{r c}, t_{p l}$ and $l_{r c}$ are the speed of re-coater, layer thickness, and length of re-coater responsible for delivering and spreading powder at the surface of the base plate (Figure 1), respectively. After solving Equations (20) and (21), one will achieve:

$$
h_{1}=\frac{4 \forall_{2} \rho_{p} V_{r c} t_{p l} l_{r c}}{\pi W_{1} V_{s} \rho_{p}} .
$$

To print the 1st layer, the laser energy arriving at the substrate's depth $\left(Q_{s}\right)$ can be divided into two portions: (a) energy absorbed by the powder bed $\left(Q_{p}\right)$, and (b) energy used by the base-plate $\left(Q_{B S}\right)$ to generate melt-pool depth $\left(d_{1}\right)$, as [30]:

$$
Q_{S}=Q_{P}+Q_{B S} .
$$

In Equation (23), $Q_{S}$ is calculated as:

$$
Q_{S}=\alpha\left(\frac{P L}{V_{S}}\right) .
$$

Here, $L$ is the length of the printed layer. Furthermore, $Q_{P}$ can be expressed as:

$$
Q_{P}=\left(\forall_{2} \rho_{p} V_{r c} t_{p l} l_{r c} \frac{L}{V_{S}}\right) C_{p}^{*} .
$$

Besides, $Q_{B S}$ has been calculated as [30]: 


$$
Q_{B S}=\frac{\pi}{6} W_{1} d_{1} L \rho_{S} C_{S}^{*}
$$

In Equation (26), $C_{s}^{*}$ is the modified specific heat, which can be calculated using enthalpy fusion $\left(L_{f s}\right)$, temperature difference, and specific heat $\left(C_{s}\right)$ of the substrate material as [30]:

$$
C_{s}^{*}=\frac{L_{f s}}{T_{m s}-T_{o}}+C_{s}
$$

Combining Equations (23)-(26) results in:

$$
d_{1}=\frac{\left[\forall_{2}\left(P L-V_{s}\right)\right]-\left[\forall_{2} \rho_{p} V_{r c} t_{p l} l_{r c} L C_{p}^{*}\right]}{\left[\frac{\pi}{6} \rho_{s} V_{s} W_{1} L C_{s}^{*}\right]} .
$$

The printed layer's width, height, and depth can be estimated using Equations (19), (22), and (28), respectively.

\subsection{Multi-Layer Printing}

For a given row, the depth of each printed layer is constant. Considering the 1st and 2nd rows, after depositing the layers in the 1st row, the laser beam generates a melt-pool depth in 1st layer to make bonding between 2 nd and 1st layers. All printed layers have the same height and melt-pool depth for a given row. Figure 2a shows that 1st layer with the dimensions $\left(L \times W_{1} \times h_{1}\right)$ is printed with a melt-pool depth $\left(d_{1}\right)$ in the substrate (base plate). In LPBF, hatch distance $(H)$ is essential for printing multiple layers, which defines the $O L$ between two adjacent layers, shown by blue color in Figure $2 \mathrm{~b}$. This $O L$ decreases the net width of the final manufactured part. To deposit the next row containing $n$-layers, the re-coater spreads a powder layer melted by the laser beam to a depth in the previously deposited layer to make a bonding. It reduces the net height of the manufactured component.

(a)

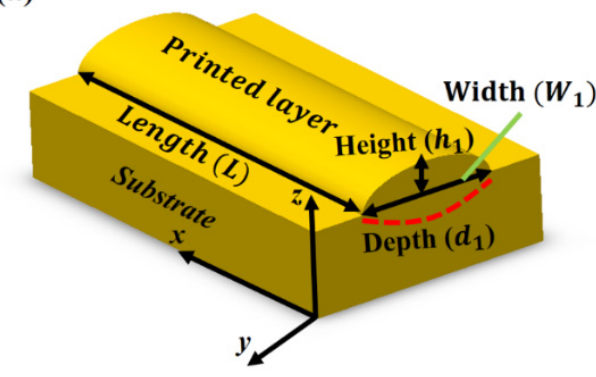

(b)

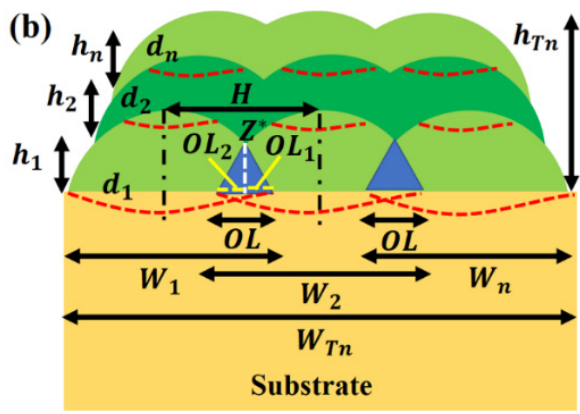

Figure 2. Schematic of laser powder bed fusion printing in the case of the (a) single-layer and (b) multi-layers.

The 1st layer overlapping on the 2 nd layer $\left(O L_{1}\right)$ can be calculated as:

$$
O L_{1}=\frac{W_{1}-H}{2}
$$

Similarly, the 2nd layer overlapping on the 1st layer $\left(O L_{2}\right)$ is expressed as:

$$
O L_{2}=\frac{W_{2}-H}{2}
$$

It is worthy of mentioning here that $W_{1}$ and $W_{2}$ are known as the operating conditions which are kept fixed. The total $O L$ can be determined as:

$$
O L=O L_{1}+O L_{2}
$$


Using Assumption 4, the area of $O L$ can be calculated using the formula for an equilateral triangle area as:

$$
\text { Area of } O L=\frac{\sqrt{3}}{4}(O L)^{2}
$$

The $O L$ intersection $\left(Z^{*}\right)$ can be calculated as:

$$
Z^{*}=\frac{\sqrt{3}}{2} O L
$$

The total width, after printing the two layers $\left(W_{T 2}\right)$ in the 1st row, is expressed as:

$$
W_{T 2}=W_{1}+W_{2}-(O L) .
$$

After estimating $W_{T 2}$, the $O L(\%)$ can be determined as:

$$
O L(\%)=\frac{O L}{W_{T 2}} \times 100 .
$$

According to Assumption 3, all primary operating conditions are fixed, which results in the same height for the 2-printed layers, analytically, given as:

$$
h_{T 1}=h_{1} .
$$

The generalized relations for overlapping between any two adjacent printed layers are given as:

$$
\begin{gathered}
O L_{n}=\frac{W_{n}-H}{2} . \\
O L_{n+1}=\frac{W_{n+1}-H}{2} . \\
O L=O L_{n}+O L_{n+1} .
\end{gathered}
$$

The total width and height for $n$-number of layers are calculated as:

$$
\begin{gathered}
W_{T n}=\sum_{i=1}^{n} W_{i}-\sum_{i=1}^{n} O L_{i} . \\
h_{T n}=\sum_{i=1}^{n} h_{i}-\sum_{i=2}^{n} d_{i} .
\end{gathered}
$$

In Equations (40) and (41), $n(=1,2,3 \ldots)$ is the number of layers.

\subsection{Average Grain Dimension Estimation for Multi-Layers Printing}

Within the 1st printed layer, the thermal stresses $\left(\sigma_{1+h}\right)$ can be calculated as [35]:

$$
\sigma_{1(t h)}=\frac{E^{*} \beta}{1-v}\left[G\left(T_{1}(x, y)-T_{o}\right)\right],
$$

where, $G, E, \beta$, and $v$ are the material's stiffness, elasticity modulus, thermal expansion coefficient, and Poisson's ratio, respectively. For the 1st layer, the thermal strain rate $\left(\varepsilon_{o}\right)$ is calculated as:

$$
\varepsilon_{1(o)}=\frac{\varepsilon_{1(t h)}}{T_{1}(x, y)-T_{o}} .
$$

Here, thermal strain $\left(\varepsilon_{t h}\right)$, can be determined as:

$$
\varepsilon_{1(t h)}=\frac{\sigma_{1(t h)}}{E^{*}},
$$

where $E^{*}$ is the modified elasticity modulus. For metals, $E^{*}$ is expressed as [36]: 


$$
E^{*}=E \frac{0.5 T_{1}(x, y)}{T_{0}}
$$

In the LPBF process, the grain formation is primarily affected by the original grain dimensions, thermal intensity distribution, and strain rate due to temperature gradient. In this work, the Johnson-Mehl-Avrami-Kohnogorov (JMAK) model $[37,38]$ is applied to compute the dynamic recrystallization $\left(X_{1(\text { drex })}\right)$ in the 1 st printed layer, expressed as $[37,38]$ :

$$
X_{1(\text { drex })}=1-\exp ^{-\left[0.693\left(\varepsilon_{1(\text { th }}-\frac{0.8 \varepsilon_{1(p)}}{\varepsilon_{1(0.5)}}\right)^{2}\right]} .
$$

Here, $\varepsilon_{1(p)}$ and $\varepsilon_{0.5}$ are the peak strain and the strain at $X_{1(\text { drex })}=0.5$, and written as [37,38]:

$$
\varepsilon_{1(0.5)}=1.214 \times 10^{-5} d_{o}^{0.13} \varepsilon_{1(o)}^{0.04} \exp ^{5.335 \times 10^{4} / R T_{1}(x, y)} .
$$

In Equation (47), $d_{o}$ is the initial grain size, which is equal to the mean powder particle diameter, $R$ is gas constant $\left(=8.3145 \mathrm{Jmol}^{-1} \mathrm{~K}^{-1}\right)$, and $\varepsilon_{1(p)}$ is expressed as $[37,38]$ :

$$
\varepsilon_{1(p)}=4.107 \times 10^{-3} \varepsilon_{1(o)}{ }^{0.06} \exp ^{1.318 \times 10^{4} / R T_{1}(x, y)} .
$$

For 1st layer, the grain size $\left(d_{1(\text { rex })}\right)$, after dynamic recrystallization, is written as [37,38]:

$$
d_{1(\text { rex })}=78.6022 \varepsilon_{1(o)}{ }^{-0.03722} \exp ^{-1902.72 / R T_{1}(x, y)} .
$$

After 1st layer printing, the average grain size $\left(d_{1(\text { avg })}\right)$ is calculated as [37,38]:

$$
d_{1(\text { avg })}=d_{o}\left(1-X_{1(\text { drex })}\right)+d_{1(\text { rex })} X_{1(\text { drex })} .
$$

For 2nd layer, the dynamic recrystallization $\left(X_{2(d r e x)}\right)$ is calculated as:

$$
\begin{gathered}
\sigma_{2(t h)}=\frac{E^{*} \beta}{1-v}\left[G\left(T_{2}(x, y)-T_{o}\right)\right] . \\
\varepsilon_{2(o)}=\frac{\varepsilon_{2(t h)}}{T_{2}(x, y)-T_{o}} . \\
\varepsilon_{2(t h)}=\frac{\sigma_{2(t h)}}{E^{*}} . \\
X_{2(\text { drex })}=1-\exp ^{-\left[0.693\left(\varepsilon_{2(t h)}-\frac{0.8 \varepsilon_{2(p)}}{\varepsilon_{2(0.5)}}\right)^{2}\right]} . \\
\varepsilon_{2(0.5)}=1.214 \times 10^{-5} d_{o}^{0.13} \varepsilon_{2(o)}{ }^{0.04} \exp ^{5.335 \times 10^{4} / R T_{2}(x, y) .} \\
d_{2(\text { rex })}=78.6022 \varepsilon_{2(o)}{ }^{-0.03722} \exp ^{-1902.72 / R T_{2}(x, y) .} \\
d_{2(\text { avg })}=d_{o}\left(1-X_{2(\text { drex })}\right)+d_{2(\text { rex })} X_{2(\text { drex })} .
\end{gathered}
$$

After depositing two layers, an average grain size $\left(d_{2 L(\operatorname{avg})}\right)$ is calculated as:

$$
d_{2 L(\operatorname{avg})}=\frac{d_{1(\operatorname{avg})}+d_{2(a v g)}}{2} .
$$

For $n$-number of layers:

$$
\begin{gathered}
\sigma_{n(t h)}=\frac{E^{*} \beta}{1-v}\left[G\left(T_{n}(x, y)-T_{o}\right)\right] . \\
\varepsilon_{n(o)}=\frac{\varepsilon_{1(t h)}}{T_{n}(x, y)-T_{o}} . \\
\varepsilon_{n(t h)}=\frac{\sigma_{n(t h)}}{E^{*}} .
\end{gathered}
$$




$$
\begin{gathered}
X_{n(\text { drex })}=1-\exp ^{-\left[0.693\left(\varepsilon_{n(t h)}-\frac{0.8 \varepsilon_{n(p)}}{\varepsilon_{n(0.5)}}\right)^{2}\right]} . \\
\varepsilon_{n(0.5)}=1.214 \times 10^{-5} d_{o}^{0.13} \varepsilon_{n(o)}{ }^{0.04} \exp ^{5.335 \times 10^{4} / R T_{n}(x, y)} . \\
d_{n(\text { rex })}=78.6022 \varepsilon_{n(o)}-0.03722 \exp ^{-1902.72 / R T_{n}(x, y) .} \\
d_{n(\text { avg })}=d_{o}\left(1-X_{n(\text { drex })}\right)+d_{n(\text { rex })} X_{n(\text { drex })} .
\end{gathered}
$$

After depositing $n$-number of layers, an average grain size $\left(d_{n L(\operatorname{avg})}\right)$ is expressed as:

$$
d_{n L(\operatorname{avg})}=\sum_{i=1}^{n} \frac{d_{i(\operatorname{avg})}}{i}
$$

Here, $i=1,2,3, \ldots, n$ (number of printed layers).

\section{Material and Methods}

To validate the developed model, LPBF experiments were carried out using an ENAVISION 120 equipment (ERMAKSAN, Bursa, Turkey). This machine utilizes fiber laser and operates using maximum $300 \mathrm{~W}$ laser power and $11 \mathrm{~m} / \mathrm{s}$ laser scanning speed. The focused laser spot size is $55 \mu \mathrm{m}$. For ENAVISION 120, further details can be obtained from Ref. [39]. Figure 3a shows the ENAVISION 120 machine utilized to validate the modelling results, Figure $3 \mathrm{~b}$ provides the nomenclature of machine parts, and Figure $3 \mathrm{c}$ shows the $\mathrm{Co}-\mathrm{Cr}$ specimens printed by LPBF.

(a)

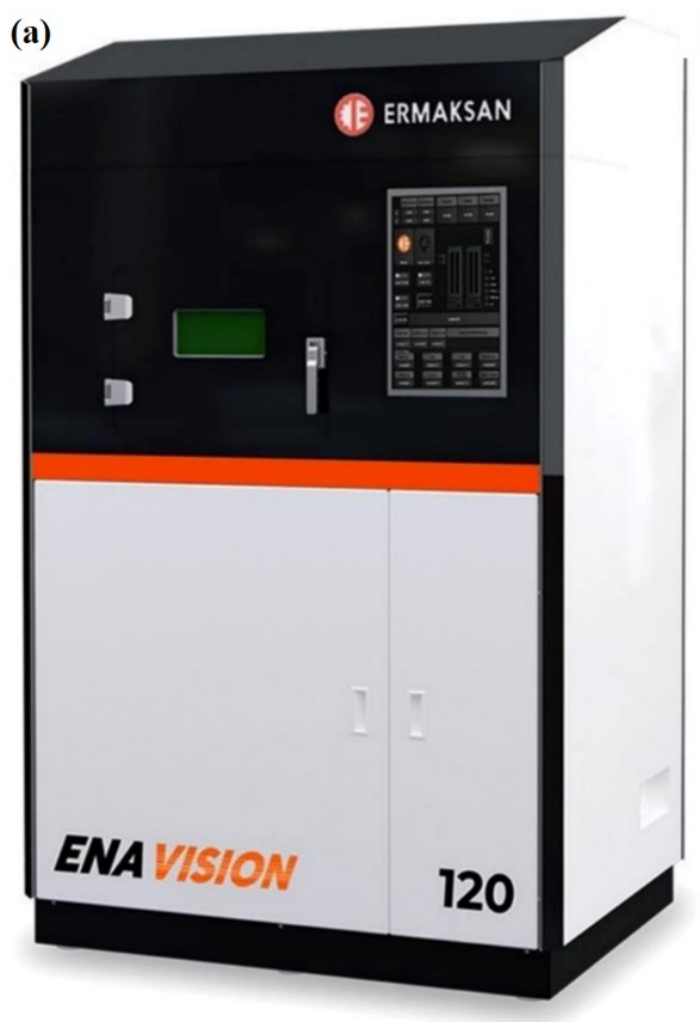

(b)

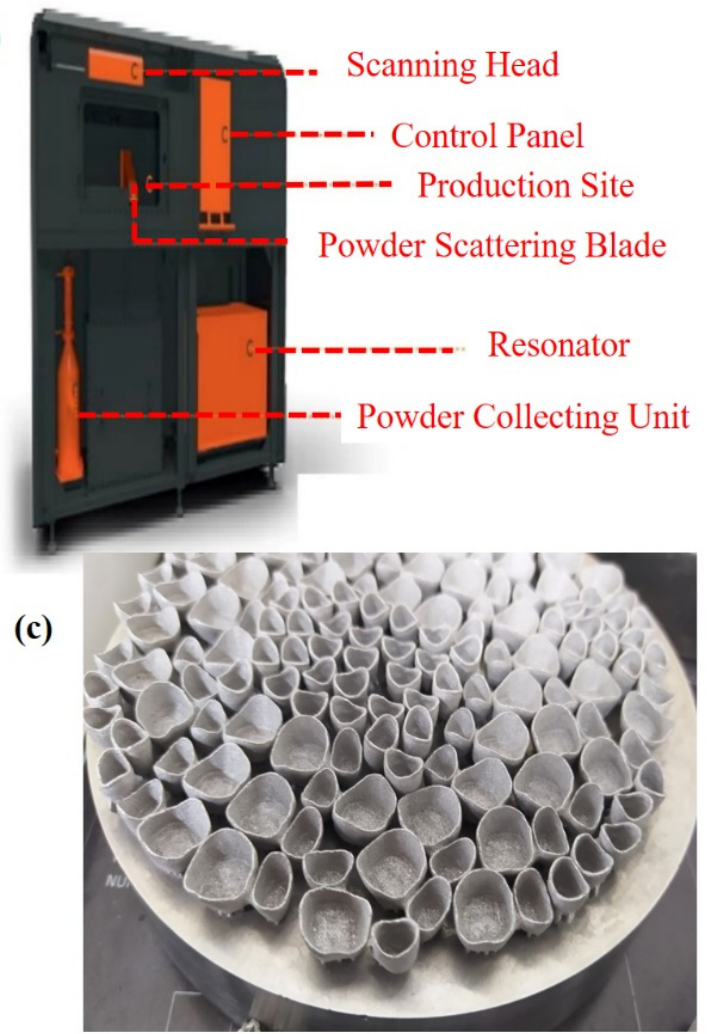

Figure 3. (a) ENAVISION 120 machine, (b) nomenclature of the machine, and (c) $\mathrm{Co}-\mathrm{Cr}$ specimen printed by LPBF.

For printing, Cobalt-chromium (Co-Cr) powder, made by ERMAKSAN, Turkey, was used in an 18-44 $\mu \mathrm{m}$ particle size range. All samples were prepared with 10 (length) $\times$ 10 (width) $\times 10$ (height) $\mathrm{mm}^{3}$ dimensions; however, cylindrical supports having $2 \mathrm{~mm}$ dimensions were used for an easy removal of the printed samples. For experimentation, 
laser power (A1-A5), laser scanning speed (B1-B5), and hatch distance (C1-C5) were varied, while the powder layer thickness was kept constant. Table 1 compiles the operating conditions used to print $\mathrm{Co}-\mathrm{Cr}$ samples.

Table 1. Operating conditions to print 15 specimens via the LPBF process.

\begin{tabular}{ccccc}
\hline Sample No. & $\begin{array}{c}\text { Laser Power } \\
(\mathbf{W})\end{array}$ & $\begin{array}{c}\text { Laser Scanning } \\
\text { Speed }(\mathbf{m m} / \mathbf{s})\end{array}$ & $\begin{array}{c}\text { Hatch Distance } \\
(\boldsymbol{\mu m})\end{array}$ & $\begin{array}{c}\text { Powder Layer } \\
\text { Thickness }(\boldsymbol{\mu m})\end{array}$ \\
\hline A1 & 200 & 900 & 0.05 \\
A2 & 190 & 900 & 0.05 \\
A3 & 180 & 900 & 0.05 \\
A4 & 170 & 900 & 0.05 \\
A5 & 160 & 900 & 0.05 & \\
B1 & 180 & 1000 & 0.05 & \\
B2 & 180 & 1200 & 0.05 & \\
B3 & 180 & 1400 & 0.05 & \\
B4 & 180 & 1600 & 0.05 & \\
B5 & 180 & 1800 & 0.05 & \\
C1 & 180 & 1100 & 0.065 \\
C2 & 180 & 1100 & 0.06 & \\
C3 & 180 & 1100 & 0.055 \\
C4 & 180 & 1100 & 0.05 \\
C5 & 180 & 1100 & 0.045 \\
\hline
\end{tabular}

Figure 4 displays the methodology applied to determine the microstructure via SEM analysis. Before carrying out the SEM analyses, the cross-sections with 1 (length) $\times 1$ (width) $\times 1$ (thickness) $\mathrm{mm}^{3}$ dimensions were prepared for all the samples from the center of the printed cubes. All the samples were ground and polished, using SAPHI 520 (ATM, Mammelzen, Germany) equipment for microstructure analysis prior to the SEM analyses. For this purpose, Table 2 collects the steps applied for mirror-like polishing. All the samples were etched for $40 \mathrm{sec}$ with $\mathrm{HCL}: \mathrm{HNO}_{3}$ (3:1) solution as mentioned in Table 2. Later on, SEM was conducted at the prepared cross-sections, perpendicular to the build-direction. At $40 \mu \mathrm{m}$ SEM magnification, several un-melted powder particles were analyzed. The same procedure was applied for all the deposited samples to correlate operating conditions and dendrite grain formation. It is worth mentioning that all the samples were printed and solidified at room temperature.

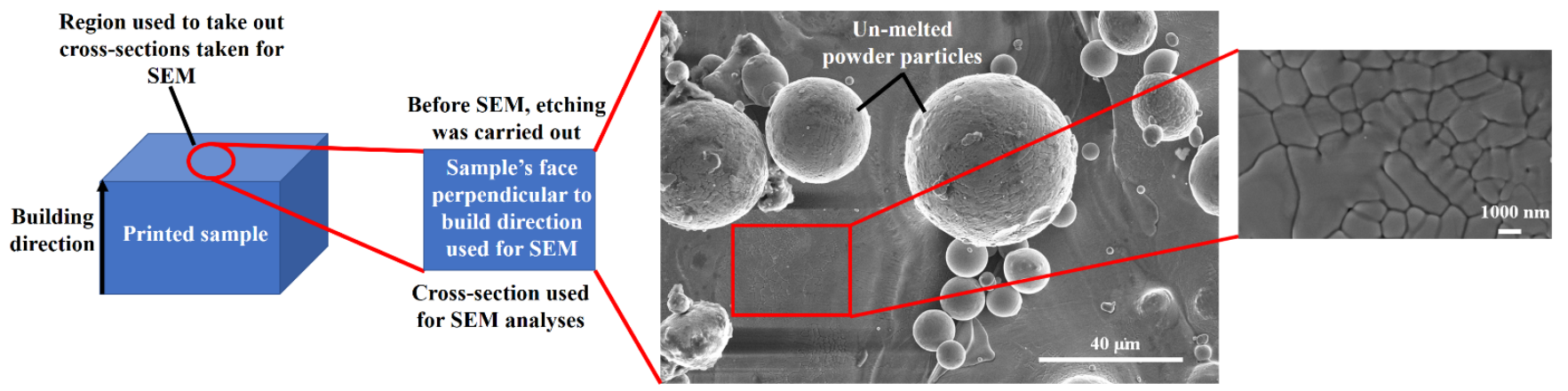

Figure 4. The methodology applied to conduct scanning electron microscopy (SEM) on the printed parts.

After preparation, the samples were examined with SEM by ApreoS instrument (Thermo Fisher Scientific, Waltham, MA, USA) and introduced in an image processing software "Image J" to quantify average grain size. The steps used in "ImageJ" software are provided in Figure $5 \mathrm{a}-\mathrm{d}$. 
Table 2. Step-by-step procedure to carry out grinding and polishing.

\begin{tabular}{|c|c|c|c|c|c|}
\hline Name of Step. & $\begin{array}{l}\text { Item Used for } \\
\text { Processing }\end{array}$ & $\begin{array}{l}\text { The Fluid Used for Sample } \\
\text { Processing }\end{array}$ & Revolution/min & $\begin{array}{l}\text { Applied Load } \\
\text { (N) }\end{array}$ & Time \\
\hline Grinding & $\begin{array}{l}\text { Silicon carbide } \\
\text { paper P320 }\end{array}$ & Water & 250 & 28 & Until plane \\
\hline \multirow{3}{*}{ Polishing } & Alpha & $\begin{array}{l}\text { Solution }(9.0 \mu \mathrm{m} \text { with } \\
\text { diamond })\end{array}$ & 150 & 24 & $5.0 \mathrm{~min}$ \\
\hline & Gamma & $\begin{array}{c}\text { Solution }(3 \mu \mathrm{m} \text { with } \\
\text { diamond })\end{array}$ & 150 & 24 & $5.0 \mathrm{~min}$ \\
\hline & Lambda & $\begin{array}{l}\text { Solution }(0.06 \mu \mathrm{m} \text { with } \\
\text { diamond })\end{array}$ & 150 & 18 & $\begin{array}{l}2.0 \mathrm{~min} \text { (water for } \\
30 \mathrm{~s} \text { at the end) }\end{array}$ \\
\hline Etching & HCL:HNO $\mathrm{HN}_{3}(3: 1)$ & - & - & - & $40 \mathrm{~s}$ \\
\hline
\end{tabular}

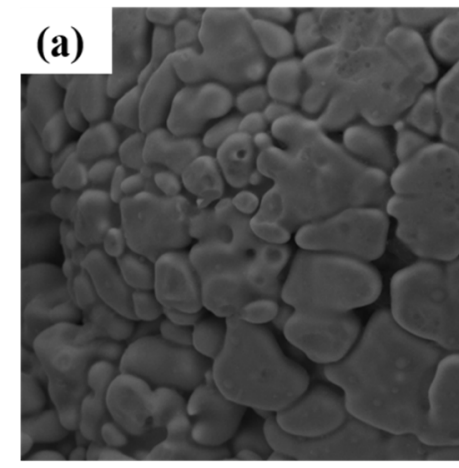

Scanning electron microscopy (SEM) image

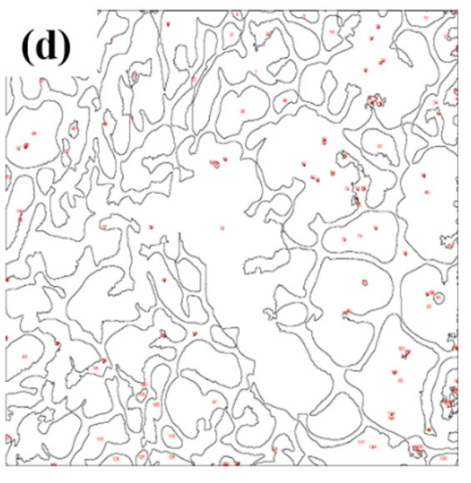

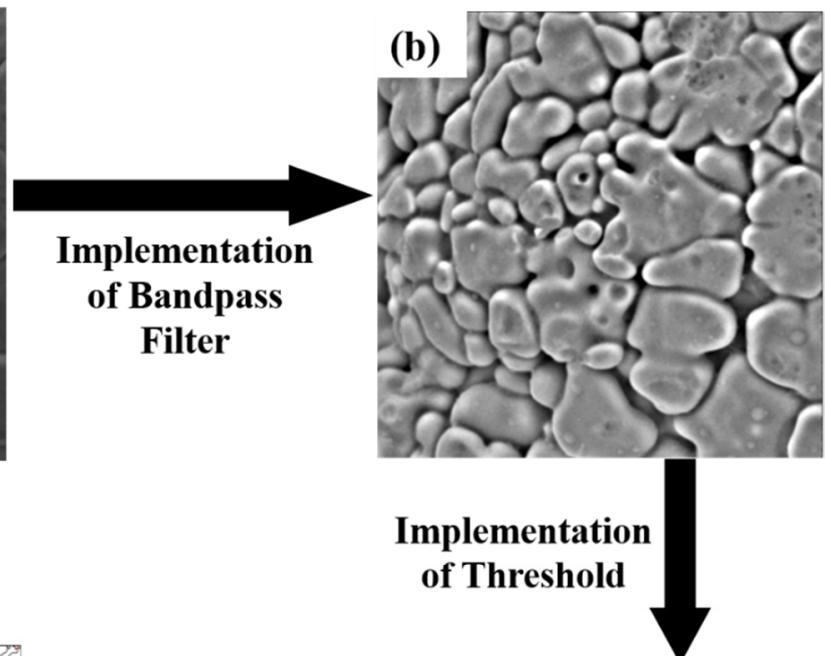

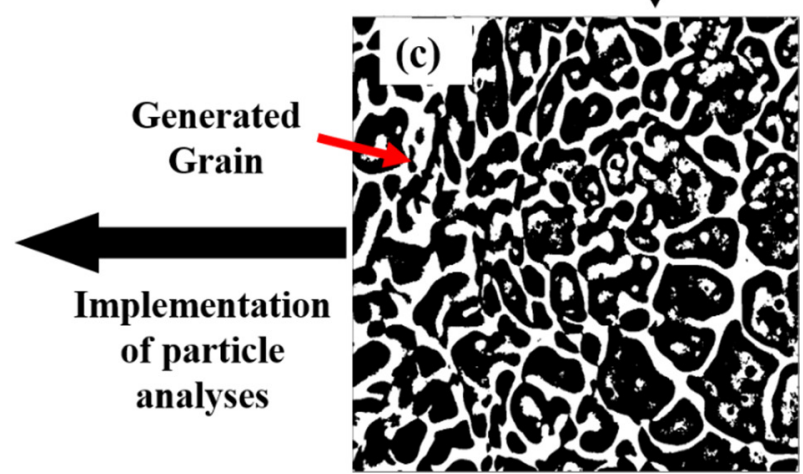

Figure 5. Implementation of "Image-J" software to calculate the average dendrite grain size in a SEM image (a) SEM image, (b) image after implementing bandpass filter, (c) image after implementing threshold filter, and (d) image achieved after particle analyses.

A Vickers hardness tester (FM-700, Future-Tech Corp, Tokyo, Japan) was used to test the hardness of the printed samples. A diamond-tip indenter was used. All items were polished to a mirror-like finish for testing, and the indentation was performed with a weight of $25 \mathrm{~g}$.

\section{Results and Discussion}

Figure $6 \mathrm{a}-\mathrm{c}$ shows the SEM images of Co-Cr powder particles at $500 \mu \mathrm{m}, 200 \mu \mathrm{m}$, and $50 \mu \mathrm{m}$ resolutions, respectively. 

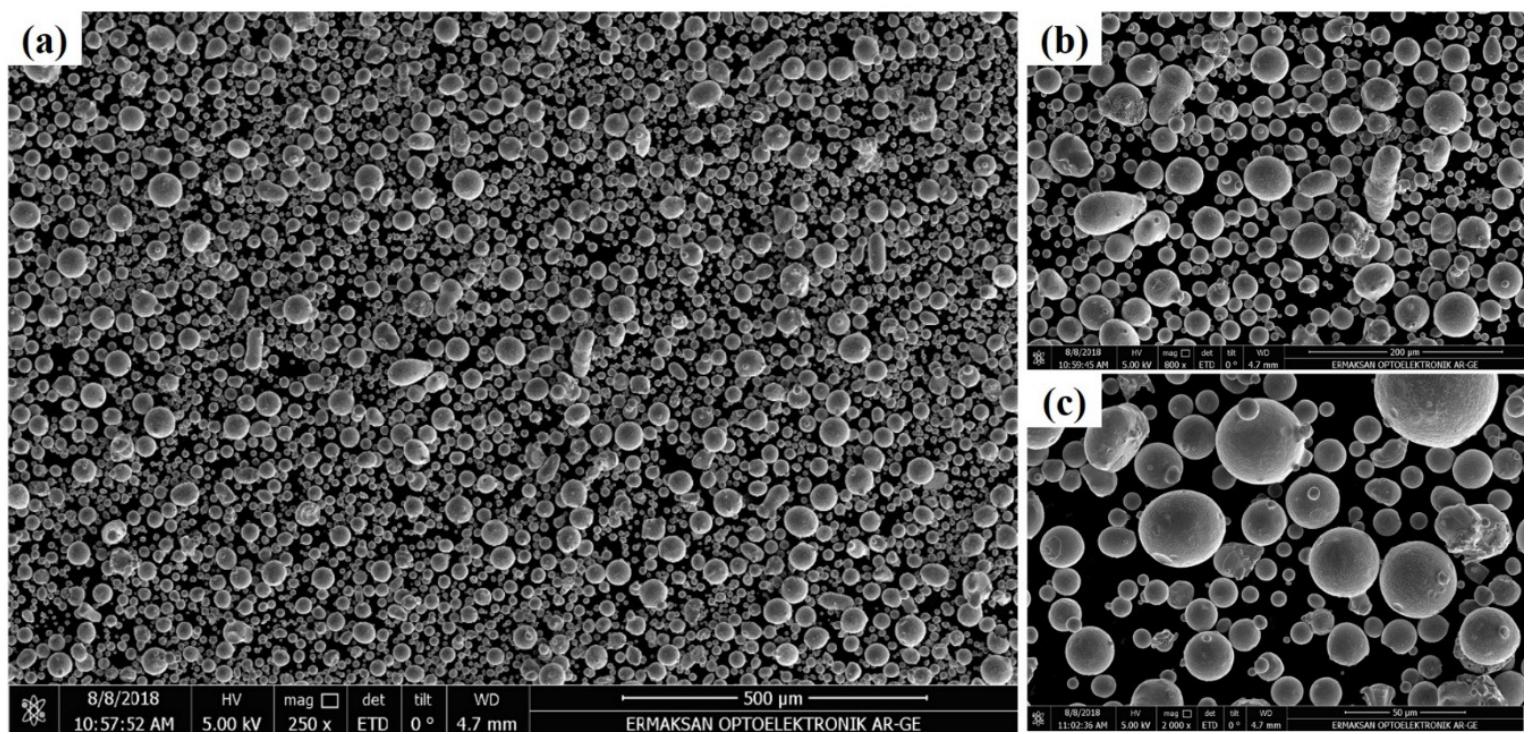

Figure 6. SEM images of Co-Cr powder particles (a) $500 \mu \mathrm{m}$, (b) $200 \mu \mathrm{m}$ and (c) $50 \mu \mathrm{m}$.

Figure $7 \mathrm{a}, \mathrm{b}$ present the 15 samples with dimensions $10 \times 10 \times 5 \mathrm{~mm}^{3}$, under different views, printed by LPBF. Cylindrical supports were used as the base of the samples, which helped an easy detachment of the workpieces from the substrate. On the other hand, a post-processing technique such as grinding is needed to smoothen the base region of the printed parts. From the images, one can observe the alphabetical classification as provided in Table 1.

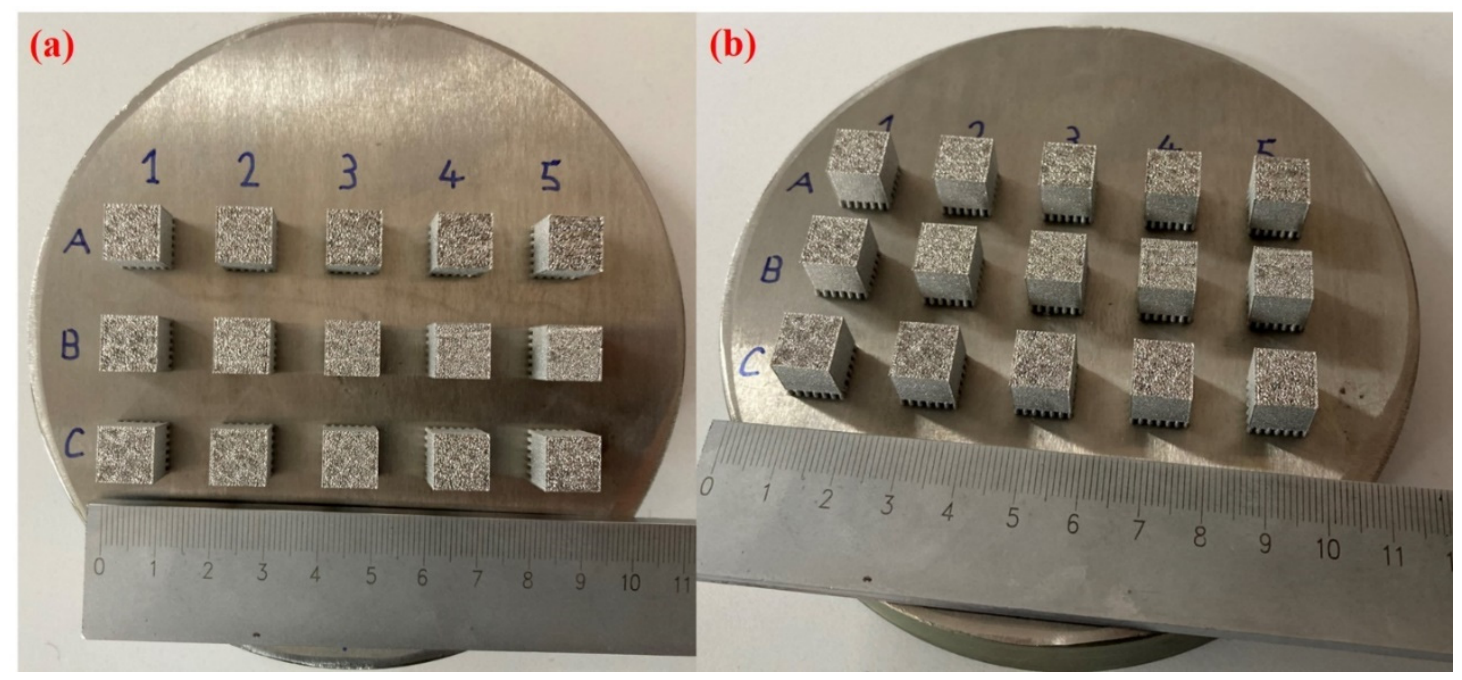

Figure 7. Fifteen samples printed using cylindrical supports by laser powder bed fusion process (a) top view and (b) inclined view.

Figure 8 shows the morphologies of the 15 printed samples. A lack of fusion (LOF) defect has been identified in the printed samples, caused by the lack of energy input during the LPBF printing. In this type of defect, poor bonding and un-melted region are two primary reasons. A laser beam melts metallic powder particles selectively in the LPBF process. When the laser energy input is low, the diameter of the molten pool becomes small due to insufficient overlap between the tracks. Inadequate layer overlap between the scan tracks results in the un-melted regions formations. Remelting these powders becomes extremely difficult while adding a subsequent layer. As a result, the LPBF-fabricated part develops partial fusion holes. If the laser energy input is insufficient to induce a sufficient melt pool depth, LOF defects may occur due to insufficient interlayer bonding. Consequently, LOF 
defects in the scan tracks and deposited layers are frequently encountered. Additionally, the surface of a faulted area becomes rough, contributing to the molten metal's inefficient flow, resulting in interlayer defects. Interlayer defects may gradually develop and propagate upward during a continuous deposition process for multi-layers printing [40,41]. From the figures, it can be analyzed that all the samples yield LOF-based defects. The areas marked with a red-colored square have been used for microstructure calculation utilized to validate the developed model and presented subsequently.

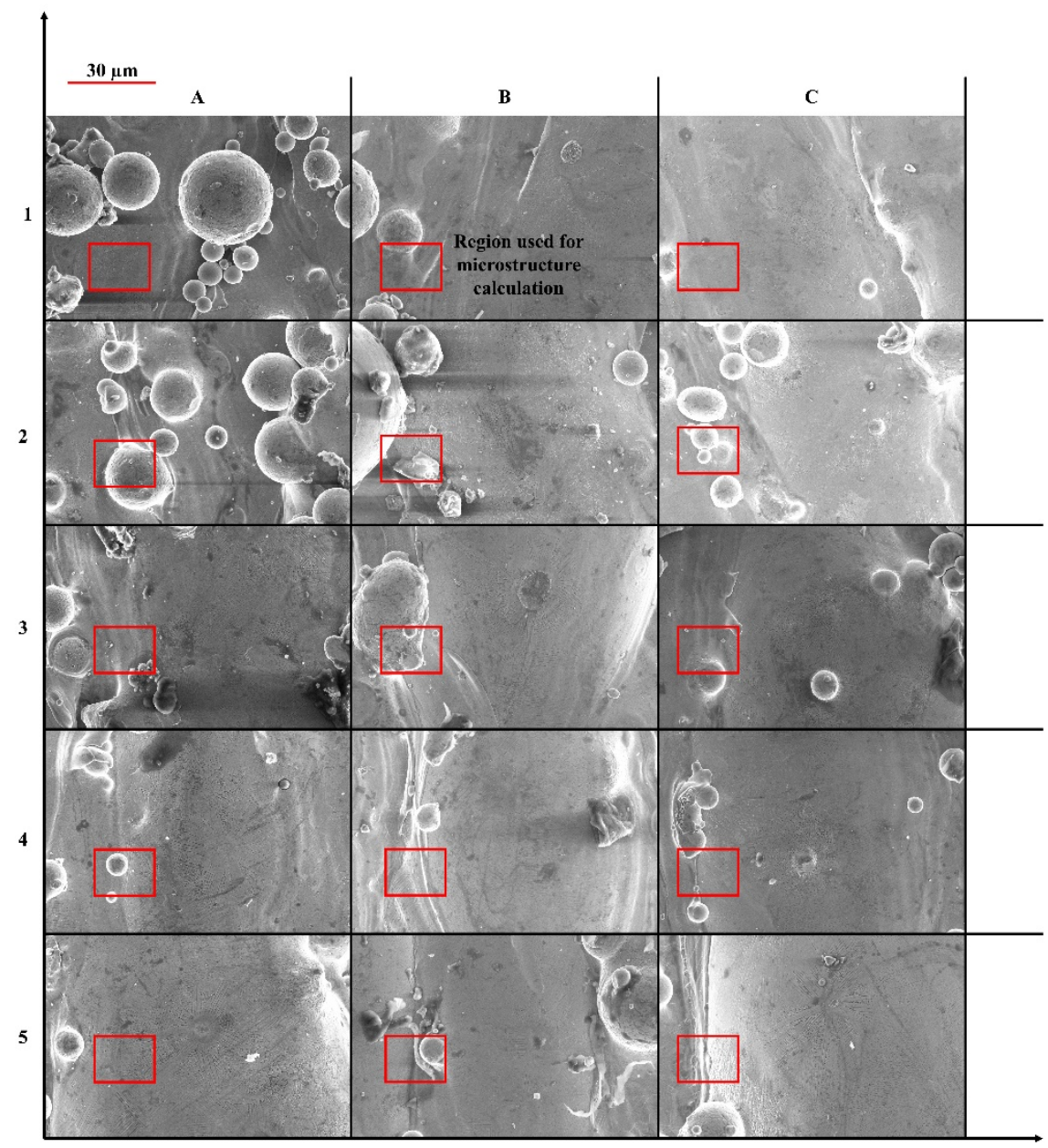

Figure 8. Morphologies of 15 printed samples with lack of fusion defects: A1-A5 (1st column), B1-B5 (2nd column), and C1-C5 (3rd column).

Figure 9 shows SEM images of the 15 LPBF-ed samples. On the one hand, from Figure 9 , it can be seen that a change in operating conditions only affects the dendrite grain dimensions and yields grains with a combination of two shapes: (a) near to circular and (b) elongated. On the other hand, the type of dendrite grain structure is a "single matrix phase of Co-based $\gamma$ (FCC)" as identified based on ref. [42]. Kit et al. [42] carried out the $x$-ray diffractometry (XRD) of LPBF-ed Co-Cr alloys. It was found that the Co-Cr samples produced by LPBF presented the single matrix phase of Co-based $\gamma$-FCC-structures.

To validate the simulation model estimation for the printed layer's width and depth, the authors have opted the published data from the study of Wan et al. [43]. In the mentioned study, the authors printed the samples with the following dimensions: $10 \times 10$ $\times 10 \mathrm{~mm}^{3}$ using Co-Cr alloy powder particles with laser power $=300 \mathrm{~W}$, laser scanning speed $=900 \mathrm{~mm} / \mathrm{s}$, and hatch distance $=0.05 \mu \mathrm{m}$. The comparison results have been presented in Figure 10. It can be seen that the model was able to estimate results with 8-10\% mean absolute deviations, which is due to the negligence of melt-flow surface tension during analytical modelling. 


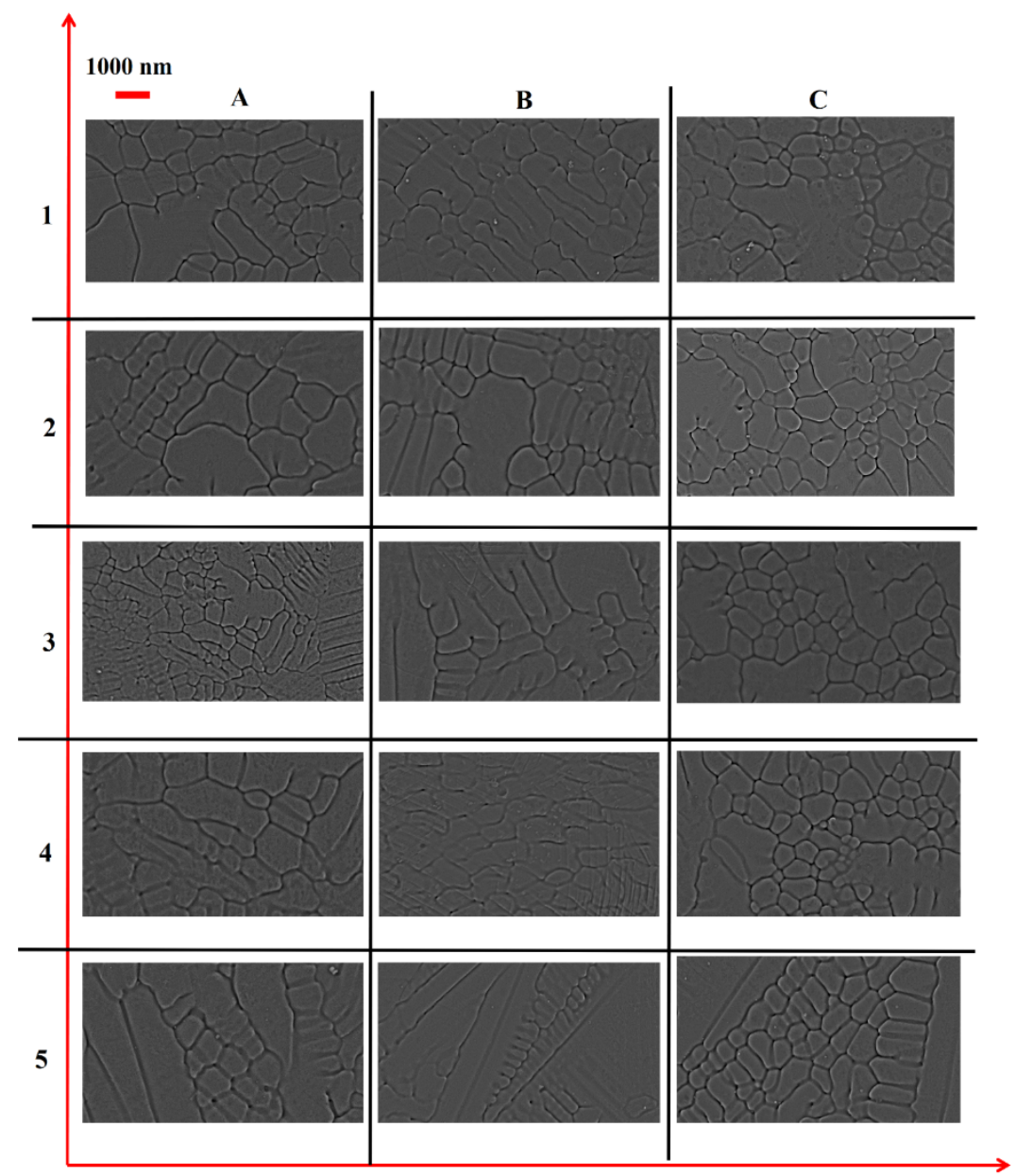

Figure 9. SEM images of A1-A5 (1st column), B1-B5 (2nd column), and C1-C5 (3rd column) samples.

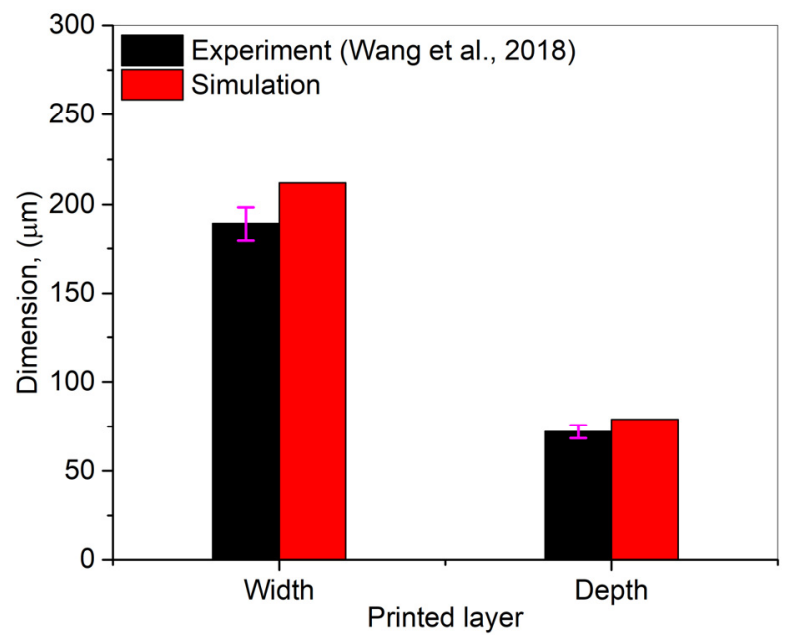

Figure 10. A comparison between experimental [43] and simulation width and depth of a single layer for Co-Cr alloy.

The thermal history plays an essential in defining the shape, grain size, and mechanical properties of [15]. In the LAM processes, the operating conditions are mainly responsible for estimating and controlling the thermal history within the deposited layers [16], which defines the grain formation. The thermal history with formed grains illustrates the deposited layers' morphology and mechanical properties [18,44]. This phenomenon becomes complex with an increment in thermal cycles [45]. Figure 11a-c explains the computational 
results for laser power $=200 \mathrm{~W}$ and laser scanning speed $=1100 \mathrm{~mm} / \mathrm{s}$. A powder layer (dimensions: length $=10 \mathrm{~mm}$, width $=10 \mathrm{~mm}$, and height $=0.05 \mathrm{~mm}$ ) is heated with a laser beam and allowed to translate along with the $x$-axis. In the case of LPBF, a powder layer has already been spread by the powder distributor whose length and width are equal to the length and width of the substrate. Figure $11 \mathrm{a}, \mathrm{b}$ shows the $3 \mathrm{D}$ temperature and contour plots when the laser beam starts moving along the powder layer. The melt pool, mushy (solid + liquid) zone, and solidified regime are visible. It is important to mention that the melt pool characteristics play a critical role in defining the solidified region's physical properties. In contrast, the mushy zone dynamics describe the evolution of microstructures and their distribution. Figure 11c,d illustrates the 3D thermal profile and contour plot as the laser beam reaches the end of the powder layer. It can be seen that as the laser beam is moving, the peak temperature value increases. This is because of the powder layer's rapid heating and slow conduction. These phenomena are responsible for introducing the residual and thermal stresses in the printed material.
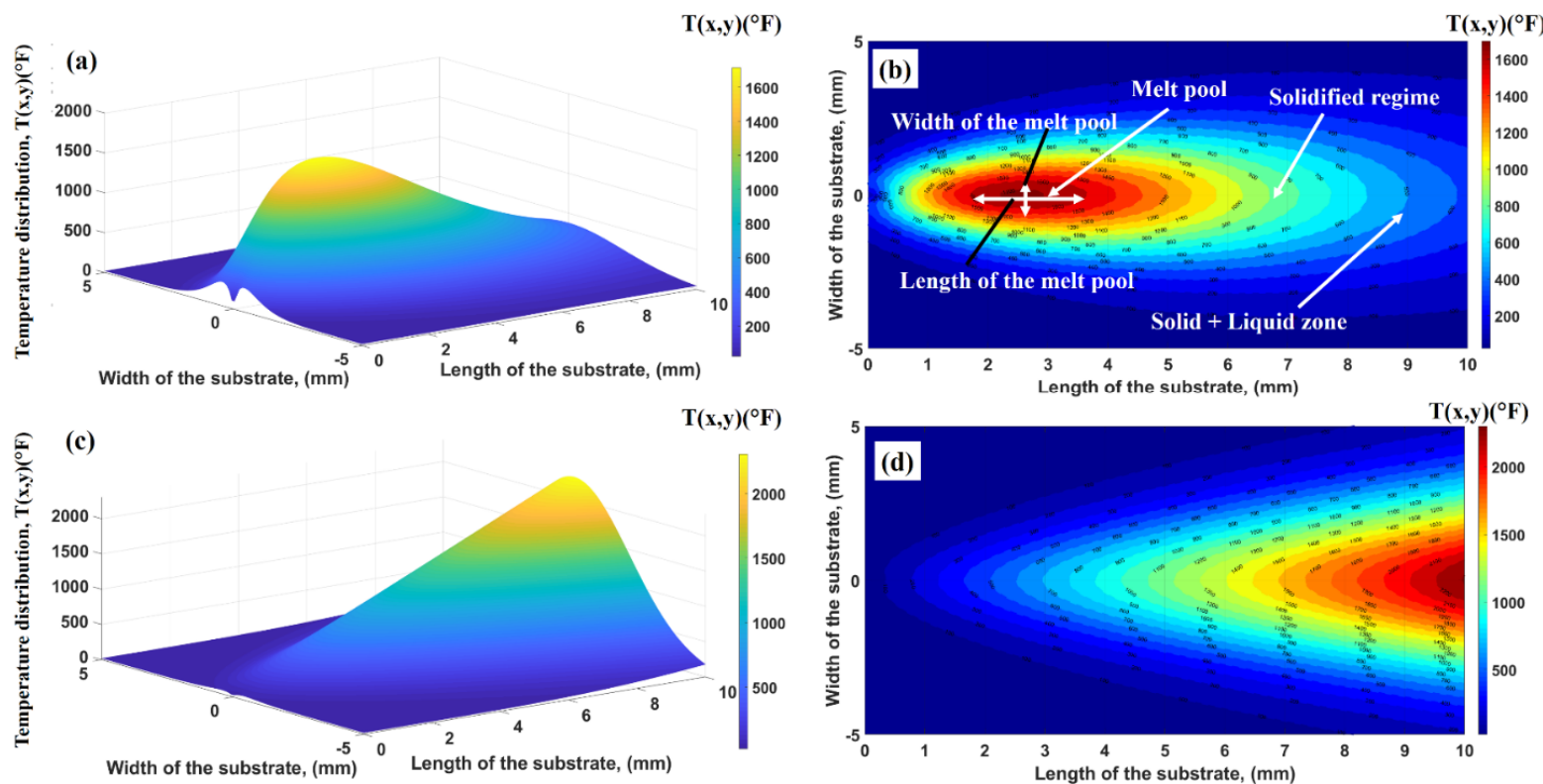

Figure 11. Three-dimensional and contour thermal distributions within the powder bed (a,b) when the laser beam is at the starting point and $(\mathbf{c}, \mathbf{d})$ when the laser beam arrives at the end of the substrate.

Figure 12 displays the temperature distribution across the depth of the powder layer. The red area shows the location of the laser beam at the top of the powder layer. The thermal isotherms travel from the top to the bottom of the layer, thus defining the melt-pool depth.

Correlations between operating conditions and average dendrite grain size formation, including laser power, laser scanning speed, and hatch distance, were determined, as shown in Figure $13 a-c$. In the case of the laser power, it was found that its increment produces fine dendrite grains. This can be explained by the fact that when the laser power increases, it results in higher energy density at a given area, ultimately increasing the thermal gradient and solidification rate. This, in turn, offers dendrite grains with smaller dimensions [46]. A direct correlation has been found between laser scanning speed and average dendrite grain size for the laser scanning speed. When the laser beam travels with a low scanning speed, the thermal gradient and solidification rate decrease with the increment in volumetric energy density due to the higher amount of accumulated heat in the sample, yielding an elevated average dendrite grain size [46]. In the case of the hatch distance, the data trend shows that an increase in the hatch distance resulted in a higher average dendrite grain size value. A hatch distance is defined as the distance between two consecutive laser scans. Usually, this distance has an inverse correspondence with deposited layers overlapping. When this distance decreases, the previously deposited layer 
experiences cyclic thermal loading, thus reducing the average grain size after depositing the successive layer. This process becomes iterative when increasing the number of layers. Additionally, the experimental results were compared with the simulation results. From Figure 13, it can be observed that the computational results showed a deviation from experimental results of $10-15 \%$. The results deduced using the current study presented better outcomes than those provided in ref. [24].

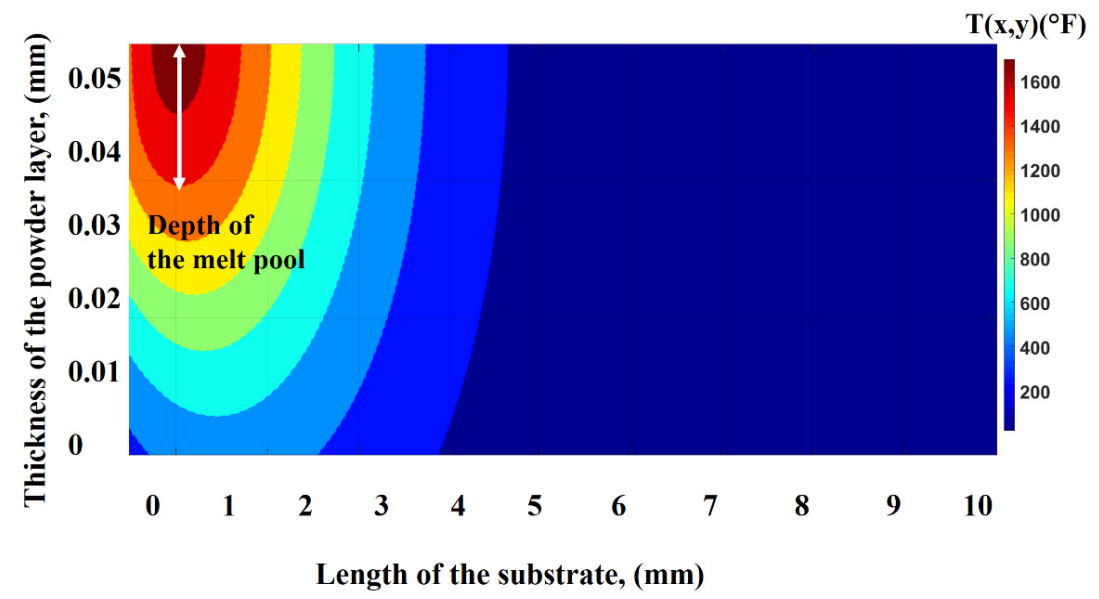

Figure 12. Thermal distributions across the thickness of the powder bed.

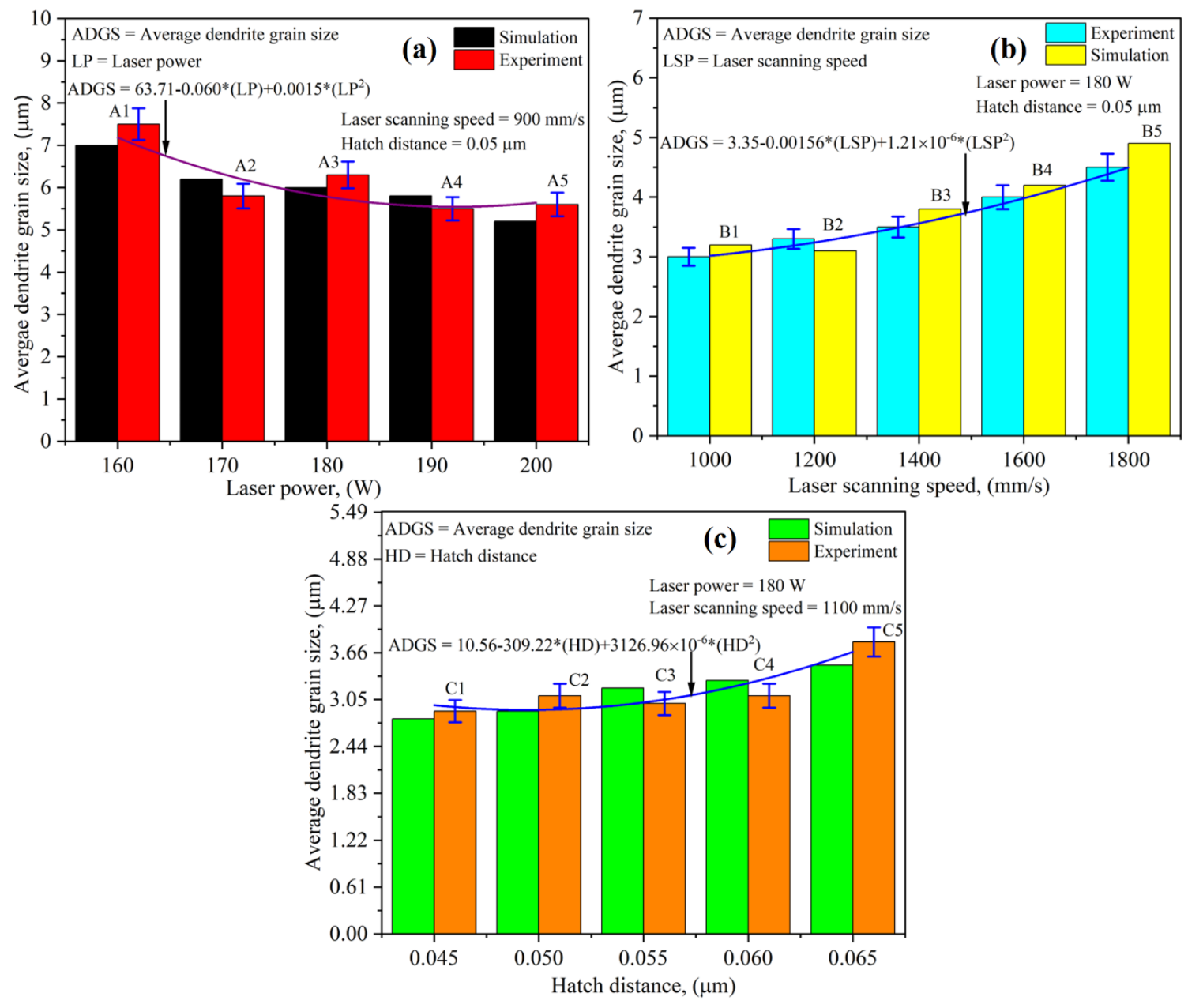

Figure 13. Effect of operating conditions on average dendrite grain size a correlation between experiments and simulations in the case of (a) laser power, (b) laser scanning speed, and (c) hatch distance. 
In Figure 14, the dendrite grain sizes as a function of volumetric energy density are presented. From the results, one can identify two trends. One is for the sample series B and $\mathrm{C}$, and another is for the sample series A only, suggesting that the solidification phenomena in sample series A, B, and C are completely different. Processing maps can be adapted to guide dendrite grain formation. Furthermore, thermal gradient $(G)$ and solidification rate $(R)$ can be translated into operating conditions to generate a process map easily interpreted. In the laser-based AM processes, $G$ and $R$ show a direct correlation [47]. A higher laser scanning speed causes an increment of $R$-value that promotes the formation of highly textured grains, while lower laser scanning speed favors equiaxed grains [47]. Conversely, increasing the laser power causes an increment in $G$ [47]. It is important to mention that the $G$ and $R$ are not constant within the melt pool [47]. $R$ is usually very high at the melt pool top and decreases linearly while moving from the top to the bottom [47].

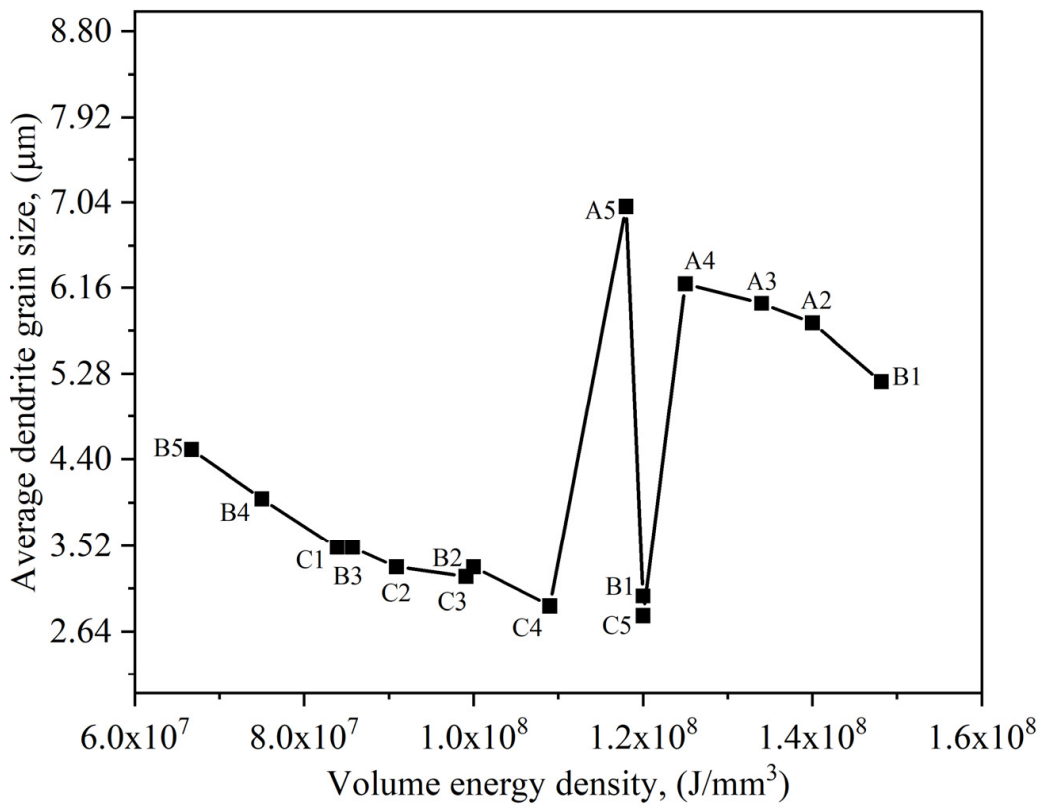

Figure 14. A correlation between volume energy density and average dendrite grain size.

A relationship between the developed average grain size and corresponding experimental hardness value is shown in Figure 15. From the results, one can analyze that the average dendrite grain size is not affecting the hardness value significantly.

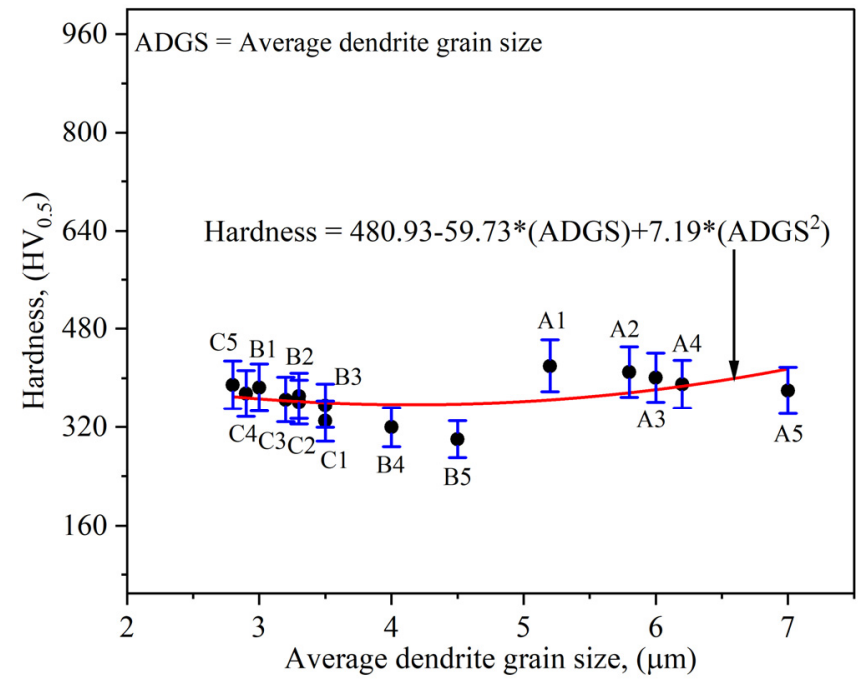

Figure 15. Relationship between average dendrite grain size and hardness value. 
Figure 16 displays the direct correlation between the laser volume energy density and hardness value. An increase in the laser volume energy density conveys more energy to a given area that causes more laser energy storage at that particular region. The indenter will need a higher load to enter that regime, resulting in an elevated hardness value. Upon comparing the results from Figures 15 and 16, it can be concluded that the hardness value is defined by the volumetric energy, involving the thermal gradient and solidification rate, thus defining the printed samples' morphology.

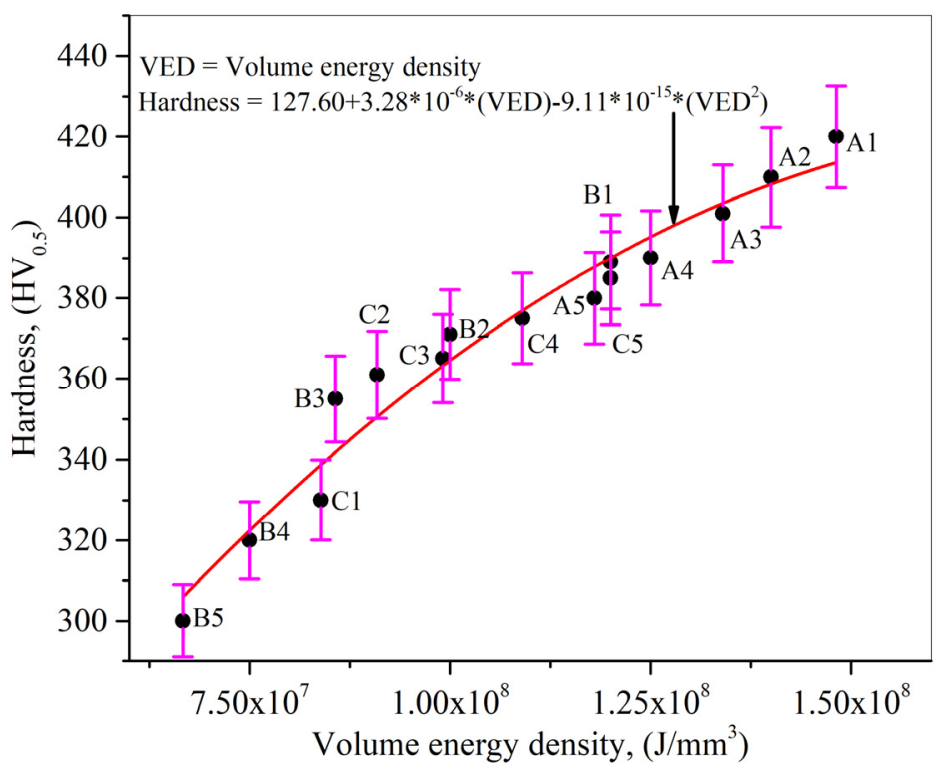

Figure 16. Correlation between volume energy density and Vickers hardness value.

\section{Conclusions}

In this study, two analytical models have been developed for LPBF printing. Initially, the dimensions of a single printed layer have been estimated using primary operating conditions, including laser power, laser scanning speed, powder layer thickness, and hatch distance. The single-layer printing was converted into multi-layer printing using a hatch distance. The corresponding thermal history was used in the Johnson-Mehl-AvramiKolmogorov model to estimate the average dendrite grain size. LPBF experiments were carried out to validate the developed model for $\mathrm{Co}-\mathrm{Cr}$ alloy printing. The developed model estimated results with a mean absolute deviation of $10-15 \%$. The following conclusions have been developed based on the current study:

- Co-Cr LPBF-ed samples presented a single matrix phase of Co-based $\gamma$-FCC-structures. It was discovered that increasing the laser power resulted in smaller average dendrite grains for laser power. For LPBF simulation, melt pool, mushy zone, and the solidified regime were identified.

- When the laser power rises, the volumetric laser energy density increases, ultimately elevating the thermal gradient and solidification rate. Thus, yielding the dendrite grains with smaller dimensions. When the laser beam translates with a low scanning speed, the thermal gradient and solidification rate decrease with the increment in volumetric energy density, resulting in elevated average dendrite grain size. When the hatch distance decreases, the previously deposited layer experiences cyclic thermal loading, thus reducing the average dendrite grain size after depositing the successive layer.

- The laser volume energy density and hardness value have been discovered to have a direct relationship between them. It can be explained that when the laser volume energy density increases, more energy is delivered to a specific location, resulting in increased laser energy storage in that area. The indenter will need more energy to enter the specific region, resulting in a greater hardness value. In addition, the thermal 
gradient and solidification rate also control the printed samples' morphology and, eventually, the final hardness value.

This study provides a time- and cost-efficient technique to identify the effect of operating conditions on average dendrite grain size. It will assist experimentalists in choosing operating conditions based on their specific requirements.

Author Contributions: Conceptualization, M.A.M., A.U.R., M.D. and F.P.; methodology, M.A.M. and A.U.R.; software, M.A.M.; validation, M.A.M., A.U.R., M.D. and F.P.; formal analysis, M.A.M., A.U.R., M.D. and F.P.; investigation, M.A.M., A.U.R., M.D., F.P. and G.P.-P.; resources, F.P., M.U.S., C.R. and I.N.M.; data curation, M.A.M., A.U.R., M.D. and F.P.; writing-original draft preparation, M.A.M. and A.U.R.; writing-review and editing, M.A.M., A.U.R. and C.R.; supervision, F.P., M.U.S., C.R. and I.N.M.; project administration, F.P., M.U.S., C.R. and I.N.M.; funding acquisition, F.P., M.U.S., C.R. and I.N.M. All authors have read and agreed to the published version of the manuscript.

Funding: This research has received financial support from the European Union's Horizon 2020 (H2020) research and innovation program under the Marie Skłodowska-Curie, grant agreement No. 764935. This research has also received funds from the Romanian Ministry of Education and Research, under Romanian National Nucleu Program LAPLAS VI-contract no. 16N/2019. The authors acknowledge with thanks the partial financial support of this work under the POC-G Contract no. 135/2016 and UEFISCDI 45/2021.

Data Availability Statement: Not applicable.

Acknowledgments: The authors acknowledge with thanks the assistance of Baiasu Flaviu Florin in conducting Vickers's hardness testing.

Conflicts of Interest: The authors declare no conflict of interest.

\section{References}

1. Mahmood, M.A.; Popescu, A.C.; Mihailescu, I.N. Metal Matrix Composites Synthesized by Laser-Melting Deposition: A Review. Materials 2020, 13, 2593. [CrossRef] [PubMed]

2. Mahmood, M.A. 3D Printing in Drug Delivery and Biomedical Applications: A State-of-the-Art Review. Compounds 2021, 1, 94-115. [CrossRef]

3. Mahmood, M.A.; Popescu, A.C. 3D Printing at Micro-Level: Laser-Induced Forward Transfer and Two-Photon Polymerization. Polymers 2021, 13, 2034. [CrossRef] [PubMed]

4. Rehman, A.U.; Mahmood, M.A.; Pitir, F.; Salamci, M.U.; Popescu, A.C.; Mihailescu, I.N. Keyhole Formation by Laser Drilling in Laser Powder Bed Fusion of Ti6Al4V Biomedical Alloy: Mesoscopic Computational Fluid Dynamics Simulation versus Mathematical Modelling Using Empirical Validation. Nanomaterials 2021, 11, 3284. [CrossRef] [PubMed]

5. Ullah, A.; Wu, H.A.; Ur Rehman, A.; Zhu, Y.B.; Liu, T.; Zhang, K. Influence of laser parameters and Ti content on the surface morphology of L-PBF fabricated Titania. Rapid Prototyp. J. 2021, 27, 71-80. [CrossRef]

6. Ansari, P.; Rehman, A.U.; Pitir, F.; Veziroglu, S.; Mishra, Y.K.; Aktas, O.C.; Salamci, M.U. Selective Laser Melting of 316L Austenitic Stainless Steel: Detailed Process Understanding Using Multiphysics Simulation and Experimentation. Metals 2021, 11 , 1076. [CrossRef]

7. Whang, S.H. Nanostructured Metals and Alloys: Processing, Microstructure, Mechanical Properties and Applications; Woodhead Publishing: Sawston, UK, 2011; pp. 15-19. [CrossRef]

8. Ma, C.P.; Guan, Y.C.; Zhou, W. Laser polishing of additive manufactured Ti alloys. Opt. Lasers Eng. 2017, 93, 171-177. [CrossRef]

9. Park, S.Y.; Kim, K.S.; AlMangour, B.; Grzesiak, D.; Lee, K.A. Effect of unit cell topology on the tensile loading responses of additive manufactured CoCrMo triply periodic minimal surface sheet lattices. Mater. Des. 2021, 206, 109778. [CrossRef]

10. Saprykin, A.A.; Sharkeev, Y.P.; Saprykina, N.; Ibragimov, E.A. The Mechanism of Forming Coagulated Particles in Selective Laser Melting of Cobalt-Chromium-Molybdenum Powder. Key Eng. Mater. 2020, 839, 79-85. [CrossRef]

11. AlMangour, B.; Luqman, M.; Grzesiak, D.; Al-Harbi, H.; Ijaz, F. Effect of processing parameters on the microstructure and mechanical properties of Co-Cr-Mo alloy fabricated by selective laser melting. Mater. Sci. Eng. A 2020, 792, 139456. [CrossRef]

12. Teng, C.; Gong, H.; Szabo, A.; Dilip, J.J.S.; Ashby, K.; Zhang, S.; Patil, N.; Pal, D.; Stucker, B. Simulating melt pool shape and lack of fusion porosity for selective laser melting of cobalt chromium components. J. Manuf. Sci. Eng. 2017, 139, 011009. [CrossRef]

13. AlMangour, B.; Grzesiak, D.; Cheng, J.; Ertas, Y. Thermal behavior of the molten pool, microstructural evolution, and tribological performance during selective laser melting of TiC/316L stainless steel nanocomposites: Experimental and simulation methods. $J$. Mater. Process. Technol. 2018, 257, 288-301. [CrossRef]

14. Arif, M.; Popescu, A.C.; Oane, M.; Chioibasu, D.; Popescu-pelin, G.; Ristoscu, C.; Mihailescu, I.N. Grain refinement and mechanical properties for AISI304 stainless steel single-tracks by laser melting deposition:Mathematical modelling versus experimental results. Results Phys. 2021, 22, 103880. [CrossRef] 
15. Mahmood, M.A.; Chioibasu, D.; Ur Rehman, A.; Mihai, S.; Popescu, A.C. Post-Processing Techniques to Enhance the Quality of Metallic Parts Produced by Additive Manufacturing. Metals 2022, 12, 77. [CrossRef]

16. Wang, Z.; Palmer, T.A.; Beese, A.M. Effect of processing parameters on microstructure and tensile properties of austenitic stainless steel 304L made by directed energy deposition additive manufacturing. Acta Mater. 2016, 110, 226-235. [CrossRef]

17. Farshidianfar, M.H.; Khajepour, A.; Gerlich, A.P. Effect of real-time cooling rate on microstructure in Laser Additive Manufacturing. J. Mater. Process. Technol. 2016, 231, 468-478. [CrossRef]

18. Wang, T.; Zhu, Y.Y.; Zhang, S.Q.; Tang, H.B.; Wang, H.M. Grain morphology evolution behavior of titanium alloy components during laser melting deposition additive manufacturing. J. Alloys Compd. 2015, 632, 505-513. [CrossRef]

19. Kumar, C.; Das, M.; Paul, C.P.; Singh, B. Experimental investigation and metallographic characterization of fiber laser beam welding of Ti-6Al-4V alloy using response surface method. Opt. Lasers Eng. 2017, 95, 52-68. [CrossRef]

20. Zinovieva, O.; Zinoviev, A.; Ploshikhin, V. Three-dimensional modeling of the microstructure evolution during metal additive manufacturing. Comput. Mater. Sci. 2018, 141, 207-220. [CrossRef]

21. Dezfoli, A.R.A.; Lo, Y.L.; Mohsin Raza, M. Microstructure and Elements Concentration of Inconel 713LC during Laser Powder Bed Fusion through a Modified Cellular Automaton Model. Crystals 2021, 11, 1065. [CrossRef]

22. Dezfoli, A.R.A.; Lo, Y.L.; Raza, M.M. Prediction of Epitaxial Grain Growth in Single-Track Laser Melting of IN718 Using Integrated Finite Element and Cellular Automaton Approach. Materials 2021, 14, 5202. [CrossRef] [PubMed]

23. Dezfoli, A.R.A.; Lo, Y.L.; Raza, M.M. 3D Multi-Track and Multi-Layer Epitaxy Grain Growth Simulations of Selective Laser Melting. Materials 2021, 14, 7346. [CrossRef]

24. Ji, X.; Mirkoohi, E.; Ning, J.; Liang, S.Y. Analytical modeling of post-printing grain size in metal additive manufacturing. Opt. Lasers Eng. 2020, 124, 105805. [CrossRef]

25. Fanfoni, M.; Tomellini, M. The Johnson-Mehl-Avrami-Kolmogorov model: A brief review. Il Nuovo Cimento D 1998, 20, 1171-1182. [CrossRef]

26. $\mathrm{Hu}, \mathrm{Y}$; $\mathrm{Li}$, J. Selective laser alloying of elemental titanium and boron powder: Thermal models and experiment verification. $J$. Mater. Process. Technol. 2017, 249, 426-432. [CrossRef]

27. Diniz Neto, O.O.; Vilar, R. Physical-computational model to describe the interaction between a laser beam and a powder jet in laser surface processing. J. Laser Appl. 2002, 14, 46-51. [CrossRef]

28. Lepski, D.; Brückner, F. Laser Cladding. In The Theory of Laser Materials Processing; Springer: Dordrecht, The Netherlands, 2009; pp. 235-279.

29. Han, L.; Liou, F.W. Numerical investigation of the influence of laser beam mode on melt pool. Int. J. Heat Mass Transf. 2004, 47, 4385-4402. [CrossRef]

30. Mahmood, M.A.; Popescu, A.C.; Hapenciuc, C.L.; Ristoscu, C.; Visan, A.I.; Oane, M.; Mihailescu, I.N. Estimation of clad geometry and corresponding residual stress distribution in laser melting deposition: Analytical modeling and experimental correlations. Int. J. Adv. Manuf. Technol. 2020, 111,77-91. [CrossRef]

31. Carslaw, H.; Jaeger, J. Conduction of Heat in Solids; Oxford University Press: Oxford, UK, 1959.

32. Optical Intensity, Explained by RP Photonics Encyclopedia; Physics, Radiometry, Energy Flux, Light Intensity. Amplitude, Electric Field, Poynting Vector. Available online: https:/ / www.rp-photonics.com/optical_intensity.html (accessed on 20 January 2022).

33. Calculating Heat Loss. Available online: http:/ / www.sensiblehouse.org/nrg_heatloss.htm (accessed on 20 January 2022).

34. How to Evaluate the Heat Dissipation of a Power Converter ? Coil Technology Corporation. Available online: https://www. powerctc.com/en/node/5028 (accessed on 20 January 2022).

35. Shalev, M.; Zvirin, Y.; Stotter, A. Experimental and analytical investigation of the heat transfer and thermal stresses in a cylinder head of a diesel engine. Int. J. Mech. Sci. 1983, 25, 471-483. [CrossRef]

36. Does the Young's Modulus Vary with Respect to Temperature? Available online: https://www.researchgate.net/post/Does_ the_Youngs_modulus_vary_with_respect_to_temperature (accessed on 30 April 2020).

37. Arisoy, Y.M.; Özel, T. Prediction of machining induced microstructure in Ti-6Al-4V alloy using 3-D FE-based simulations: Effects of tool micro-geometry, coating and cutting conditions. J. Mater. Process. Technol. 2015, 220, 1-26. [CrossRef]

38. Siciliano, J.F.; Minami, K.; Maccagno, T.M.; Jonas, J.J. Mathematical Modeling of the Mean Flow Stress, Fractional Softening and Grain Size during the Hot Strip Stress Rolling of C-Mn SoftenSteels. ISIJ Int. 1996, 36, 500-506. [CrossRef]

39. 3D Additive Manufacturing Technology. Available online: https://www.ermaksanadditive.com/en-US/3d-printers/enavision120 (accessed on 7 September 2021).

40. Zhang, B.; Li, Y.; Bai, Q. Defect Formation Mechanisms in Selective Laser Melting: A Review. Chin. J. Mech. Eng. 2017, 30, 515-527. [CrossRef]

41. Aboulkhair, N.T.; Everitt, N.M.; Ashcroft, I.; Tuck, C. Reducing porosity in AlSi10Mg parts processed by selective laser melting Addit. Manuf. 2014, 1, 77-86. [CrossRef]

42. Kim, H.R.; Jang, S.H.; Kim, Y.K.; Son, J.S.; Min, B.K.; Kim, K.H.; Kwon, T.Y. Microstructures and mechanical properties of Co-Cr dental alloys fabricated by three CAD/CAM-based processing techniques. Materials 2016, 9, 596. [CrossRef]

43. Wang, J.H.; Ren, J.; Liu, W.; Wu, X.Y.; Gao, M.X.; Bai, P.K. Effect of Selective Laser Melting Process Parameters on Microstructure and Properties of Co-Cr Alloy. Materials 2018, 11, 1546. [CrossRef] [PubMed]

44. Xu, X.; Mi, G.; Luo, Y.; Jiang, P.; Shao, X.; Wang, C. Morphologies, microstructures, and mechanical properties of samples produced using laser metal deposition with $316 \mathrm{~L}$ stainless steel wire. Opt. Lasers Eng. 2017, 94, 1-11. [CrossRef] 
45. Muvvala, G.; Patra Karmakar, D.; Nath, A.K. Online monitoring of thermo-cycles and its correlation with microstructure in laser cladding of nickel based super alloy. Opt. Lasers Eng. 2017, 88, 139-152. [CrossRef]

46. Zhang, X.; Zhou, Y.; Jin, T.; Sun, X.; Liu, L. Effect of Solidification Rate on Grain Structure Evolution during Directional Solidification of a Ni-based Superalloy. J. Mater. Sci. Technol. 2013, 29, 879-883. [CrossRef]

47. Oliveira, J.P.; LaLonde, A.D.; Ma, J. Processing parameters in laser powder bed fusion metal additive manufacturing. Mater. Des. 2020, 193, 108762. [CrossRef] 